\title{
Age-related Changes and Sex Differences in Postural Control Adaptability in Children during Periodic Floor Oscillation with Eyes Closed
}

\author{
Katsuo Fujiwara ${ }^{1)}$, Takeo Kiyota $^{2)}$, Aida Mammadova ${ }^{1)}$ and Chie Yaguchi ${ }^{1)}$ \\ 1) Department of Human Movement and Health, Graduate School of Medical Science, Kanazawa University \\ 2) Department of Psychology, Faculty of Humanities, Sapporo International University
}

\begin{abstract}
We investigated age-related changes and sex differences in adaptability of anticipatory postural control in children. Subjects comprised 449 children (4-12 years old) and 109 young adults (18-29 years old). Subjects stood with eyes closed on a force-platform fixed to a floor oscillator. We conducted five trials of 1-minute oscillation $(0.5 \mathrm{~Hz}$ frequency, $2.5 \mathrm{~cm}$ amplitude) in the anteroposterior direction. Postural steadiness was quantified as the mean speed of the center of pressure in the anteroposterior direction (CoPy). In young adults, CoPy speed decreased rapidly until the third trial for both sexes. Adaptability was evaluated by changes in steadiness. The adaptability of children was categorized as "good," "moderate," and "poor," compared with a standard variation of the mean CoPy speed regression line between the first and fifth trials in young adults. Results were as follows: (1) anticipatory postural control adaptability starts to develop from age 6 in boys and 5 in girls, and greatly improves at age $7-8$ in boys and 6 in girls; (2) the adaptability of children at age $11-12$ ( $74 \%$ of boys and $63 \%$ of girls were categorized as "good") has not yet reached the same level as for young adults; (3) the adaptability at age 11-12 for girls is temporarily disturbed due to early puberty. $J$ Physiol Anthropol 30(5): 187-194, 2011 http://www.jstage.jst.go.jp/browse/jpa2
\end{abstract}

[DOI: 10.2114/jpa2.30.187]

Keywords: anticipatory postural control, adaptability, children, age-related changes, sex difference, floor oscillation, development

\section{Introduction}

Humans perform motor actions based on a standing posture. To effectively maintain body balance in a changing environment, it is essential to develop the ability to modulate postural control during motor tasks (Bair et al., 2007). Under a dynamic balanced condition, when subjects are exposed to a postural disturbance, it is important to anticipate the disturbance in order to control posture. Previous studies have introduced periodic postural disturbances to investigate the adaptability of anticipatory postural control (Buchanan and Horak, 1999; Nardone et al., 2000; Earhart et al., 2004; Fujiwara et al., 2007).

The sensory system associated with postural control is broadly classified into the visual and nonvisual systems. A moveable-room paradigm has been used to investigate the developmental process of postural control adaptability based on the visual system (Lee and Aronson, 1974; Foster et al., 1996). In this paradigm, standing infants aged 5 months to 2 years, with eyes opened, showed the largest percentage of falls. However, from age 4 to 6 years, dominant sensory information for postural control changes from the visual to the somatosensory system, and falls still occur (Shumway-Cook and Woollacott, 1985). In children aged 7-10 years, these falls completely disappear. These developmental changes in postural control are probably due to the greater use of nonvisual information. However, the development of anticipatory postural control adaptability based on the nonvisual system in children older than 4 years is not well understood.

We have previously identified the effects of balance training in young adults, standing with eyes closed, under 1 minute of floor oscillation at $0.5 \mathrm{~Hz}$ frequency and $2.5 \mathrm{~cm}$ amplitude (Fujiwara and Ikegami, 1984). The mean speed of the center of pressure in the anteroposterior direction (CoPy) was used to evaluate postural steadiness, which improved rapidly by the third trial and reached a plateau by the fifth trial (Fujiwara et al., 1994). In addition, we established a method of evaluating adaptability of anticipatory postural control to floor oscillation with eyes closed, based on a standard value derived from the CoPy speed in young adults (Fujiwara et al., 2007). These studies indicate that when 1-minute periodic floor oscillation is applied as a postural disturbance, adaptation of postural control based on the nonvisual system can be assessed relatively rapidly, enabling the evaluation of the developmental process for adaptability. However, age-related changes and sex differences in adaptability during floor oscillation with eyes closed in childhood have not been investigated systematically 
Table 1 Physical characteristics and number of subjects by age group

\begin{tabular}{|c|c|c|c|c|c|c|c|c|c|}
\hline & & & \multicolumn{6}{|c|}{ Children } & \multirow{2}{*}{$\frac{\text { Young adults }}{18-29 \text { years }}$} \\
\hline & & & 4 years & 5 years & 6 years & $7-8$ years & $9-10$ years & $11-12$ years & \\
\hline \multirow{3}{*}{$\begin{array}{l}\text { Boys } \\
\text { (men) }\end{array}$} & Height & Mean & 100.1 & 107.3 & 113.7 & 120.9 & 131.0 & 145.2 & 171.7 \\
\hline & $(\mathrm{cm})$ & $S D$ & 4.2 & 3.7 & 4.9 & 6.6 & 6.4 & 9.5 & 5.1 \\
\hline & Weight & Mean & 15.4 & 17.7 & 20.0 & 23.7 & 29.6 & 40.1 & 63.8 \\
\hline \multirow{5}{*}{$\begin{array}{c}\text { Girls } \\
\text { (women) }\end{array}$} & & $n$ & 26 & 34 & 36 & 32 & 45 & 45 & 50 \\
\hline & Height & Mean & 99.9 & 106.7 & 113.2 & 120.9 & 132.3 & 148.2 & 158.0 \\
\hline & $(\mathrm{cm})$ & $S D$ & 3.7 & 4.8 & 4.0 & 8.4 & 8.0 & 5.6 & 5.3 \\
\hline & Weight & Mean & 14.8 & 17.3 & 19.9 & 23.1 & 30.1 & 41.0 & 51.8 \\
\hline & $(\mathrm{kg})$ & $S D$ & 1.5 & 2.2 & 2.7 & 4.7 & 6.5 & 7.7 & 6.2 \\
\hline
\end{tabular}

for a large number of subjects.

Previous studies comparing sex differences in motor development have reported that girls are faster and better coordinated than boys in the elementary school years, but these differences may disappear by adolescence (Denckla, 1973; Larson et al., 2007). These findings suggest that the developmental process of adaptability based on nonvisual systems and sex differences may change remarkably during childhood.

In the present study, we investigated adaptability during periodic floor oscillation with eyes closed in 4- to 12-year-old boys and girls as well as in young adult men and women (aged 18-29 years). Our goal was to elucidate the developmental process from premature adaptability of anticipatory postural control to adult-like adaptability based on nonvisual systems and sex differences.

\section{Methods}

\section{Subjects}

A total of 558 subjects (290 boys and men and 268 girls and women) participated in this study. Subjects were divided into seven age groups: 4, 5, 6, 7-8, 9-10, 11-12, and 18-29 years (young adults). They all were inhabitants of Kanazawa City, especially from Kanazawa University and its attached preschool and elementary school. Table 1 details the physical characteristics, sex, and number of subjects in each group. In accordance with the Declaration of Helsinki, all parents and young adults gave informed consent to participate (or for their children to participate) in the study following an explanation of the experimental protocol.

\section{Apparatus}

The experimental setup is described in detail in our previous study (Fujiwara et al., 2007). In brief, a force platform (S110; Patella, Japan), which is composed of three load cells, was used to record CoPy fluctuations. An oscillation table (PW0198; Electric Control Group, Japan) with a platform was moved sinusoidally at $0.5 \mathrm{~Hz}$ frequency and $2.5 \mathrm{~cm}$ amplitude

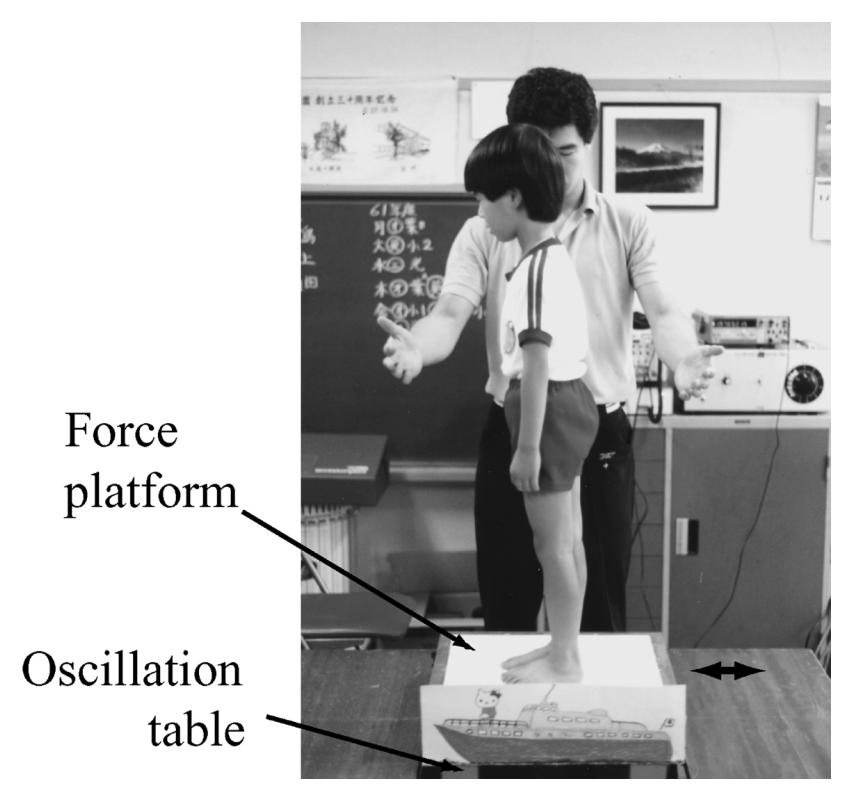

Fig. 1 Measurement of postural control adaptability during periodic floor oscillation in children.

in the anteroposterior direction (Fig. 1). We used a linear position sensor (LP10; Midori Co., Japan) to detect the frequency of table oscillation and measured this with a frequency counter (TR-5822; Advantest Co., Ltd., Japan).

We recorded signals from the force platform and from table oscillation on a digital tape recorder (RD-200TE; Teac, Japan) for subsequent analysis.

\section{Procedure}

Each subject stood on the oscillation platform with bare feet positioned $10 \mathrm{~cm}$ apart and parallel. We instructed subjects to maintain this standing posture with eyes closed, arms relaxed at the sides, and hips and knees naturally extended. Subjects maintained a quiet standing posture for 10 seconds on the stable platform, after which the platform was oscillated for 60 seconds (Fig. 1). This task was performed five times, with 60 seconds of seated rest between tasks. Subjects were supported 
by the experimenter during the first 5 seconds of the oscillation. After this, support was not provided unless the subject appeared to be in danger of falling.

Subjects were asked to keep their eyes closed to avoid input of visual information during the floor oscillation. We did not use an eye patch since children tend to dislike it through fear of darkness, and it is then sometimes difficult for them to complete a 60 -s trial. In addition, the experimenter, who supported the subjects, always checked whether they kept their eyes closed. However, in a few exceptional cases, when subjects were not able to keep their eyes closed, an eye patch was used after obtaining the subject's agreement. Subjects who could not keep their eyes closed or wear an eye patch were excluded from the experiment.

\section{Data analysis}

We calculated the mean speed of CoPy fluctuation as an index of postural steadiness. The initial 10 -second period of table oscillation was not analyzed in order to eliminate any transient changes in acceleration induced by the onset of table oscillation. For the remaining 50 seconds, the electrical CoPy signal was transmitted to a computer (PC-286LS; Epson, Japan) via an A/D converter (PIO9045; I/O-data, Japan) at 20 $\mathrm{Hz}$ and 12-bit resolution. These CoPy signals were smoothed using a five-point moving average, and mean speed of CoPy $(\mathrm{mm} / \mathrm{s})$ for 50 seconds was then calculated. To eliminate the influence of height on center of mass, we corrected the CoPy speed measurements for subject height and converted measurements into values per $100 \mathrm{~cm}$. These formulas have been described in our previous study (Fujiwara et al., 2007). If subjects opened their eyes during table oscillation and again closed them, then the data from 10 seconds after they closed their eyes were used. In addition, if subjects either moved their feet or required support from the experimenter during table oscillation, we discarded the related data (from onset of the interrupting event to 5 seconds after a stable posture was recovered).

The stepping movement during floor oscillation was observed for both sexes aged 4 to 6 , but not 7 years and older. In the first trial, the mean times for which CoPy speed was calculated based on standing without stepping for 4,5 , and 6 years in both sexes, were $22 \mathrm{~s}(S D=13), 28 \mathrm{~s}(S D=12)$, and $34 \mathrm{~s}$ $(S D=13)$, respectively. The mean times at the fifth trial for 4 , 5 , and 6 years in both sexes were $32 \mathrm{~s}(S D=13), 40 \mathrm{~s}(S D=11)$, and $44 \mathrm{~s}(S D=9)$, respectively.

We have previously reported that in a periodic oscillation task, steadiness of standing posture in all young adults improved rapidly until the third trial, with no significant change in the fourth or fifth trials, and all data from young adults were distributed within $\pm 2 \mathrm{SE}$ (SE: standard error) of the regression line between CoPy speed in the first and fifth trials (Fujiwara et al., 2007). In addition, we have indicated that the criterion of postural control adaptability based on the regression line and SE in young adults enabled evaluation of an individual's adaptability, and have proved the validity of the criterion (Fujiwara et al., 2007). Similarly, in present study, we have evaluated each individual's adaptability of postural control based on the regression line and SE between CoPy speed in the first and fifth trials in young adults as "good" $(<+2 \mathrm{SE})$, "moderate" (between +2SE and $+4 \mathrm{SE})$, or "poor" $(>+4 \mathrm{SE})$. Subjects dependent on the experimenter's support to complete the trial were also classified as "poor." However, we assessed adaptability only for individuals who exhibited mean speeds above $47 \mathrm{~mm} / \mathrm{s}$ in the first trial, as subjects with lower first trial speeds have relatively low adaptation requirements (Fujiwara et al., 2007). The number of subjects with mean speeds below $47 \mathrm{~mm} / \mathrm{s}$ in the first trial were $0,0,1$, $1,0,10$, and 28 in boys (and men), and 0, 0, 0, 0, 0, 4, and 24 in girls (and women) aged 4, 5, 6, 7-8, 9-10, 11-12, and $18-29$ years, respectively.

\section{Statistical analysis}

Shapiro-Wilks tests confirmed that all data satisfied the assumption of normality. Three-way analysis of variance (ANOVA) was performed to study the effects of trials, age, and sex on CoPy speed. One-way repeated-measures ANOVA was used to test for differences in mean speed of CoPy across the five trials. For all analyses, Greenhouse-Geisser adjustments to the degrees of freedom were applied where appropriate. Posthoc multiple-comparison analysis was performed using Dunnett's test to determine significant differences between the first trial and the other trials. Following Levene's tests of equal variance, ANOVA was used to test for age-related differences of CoPy speed. To examine the differences provided by ANOVA, post-hoc multiple-comparison analysis using a Games-Howell test was performed. In addition, Welch's $t$-test was used to test the sex differences in CoPy speed in each age group. The chi-square test was used to study the effect of age groups on the number of subjects in each category of adaptability. The value of the standardized residual was used to determine what categories were major influences on a significant chi-square test statistic. Bonferroni-adjusted Fisher's exact test was used to compare the percentage of subjects in the good and poor categories between adjacent age groups. We used the Mann-Whitney $U$-test to evaluate sex differences in distribution tendency. The alpha level was set at $p<0.05$. Therefore, the critical value for a standardized residual was set at -1.96 and +1.96 . All statistical analyses were performed using SPSS 14.0J (SPSS, Japan).

\section{Results}

Figure 2 shows changes in mean CoPy speed across the five trials. Three-way ANOVA in CoPy speed indicated significant main effects of trials and age and an interaction between trials and age (trials: $F_{3.3,1768.8}=133.2$; age: $F_{6,544}=116.6$; trials $\times$ age: $\left.F_{19.5,1768.8}=3.8, p<0.001\right)$. However, a main effect of sex and interactions between sex and other factors were not observed due to the large variation in CoPy speed among the trials and sex factor. Thus, for more detailed analysis, 


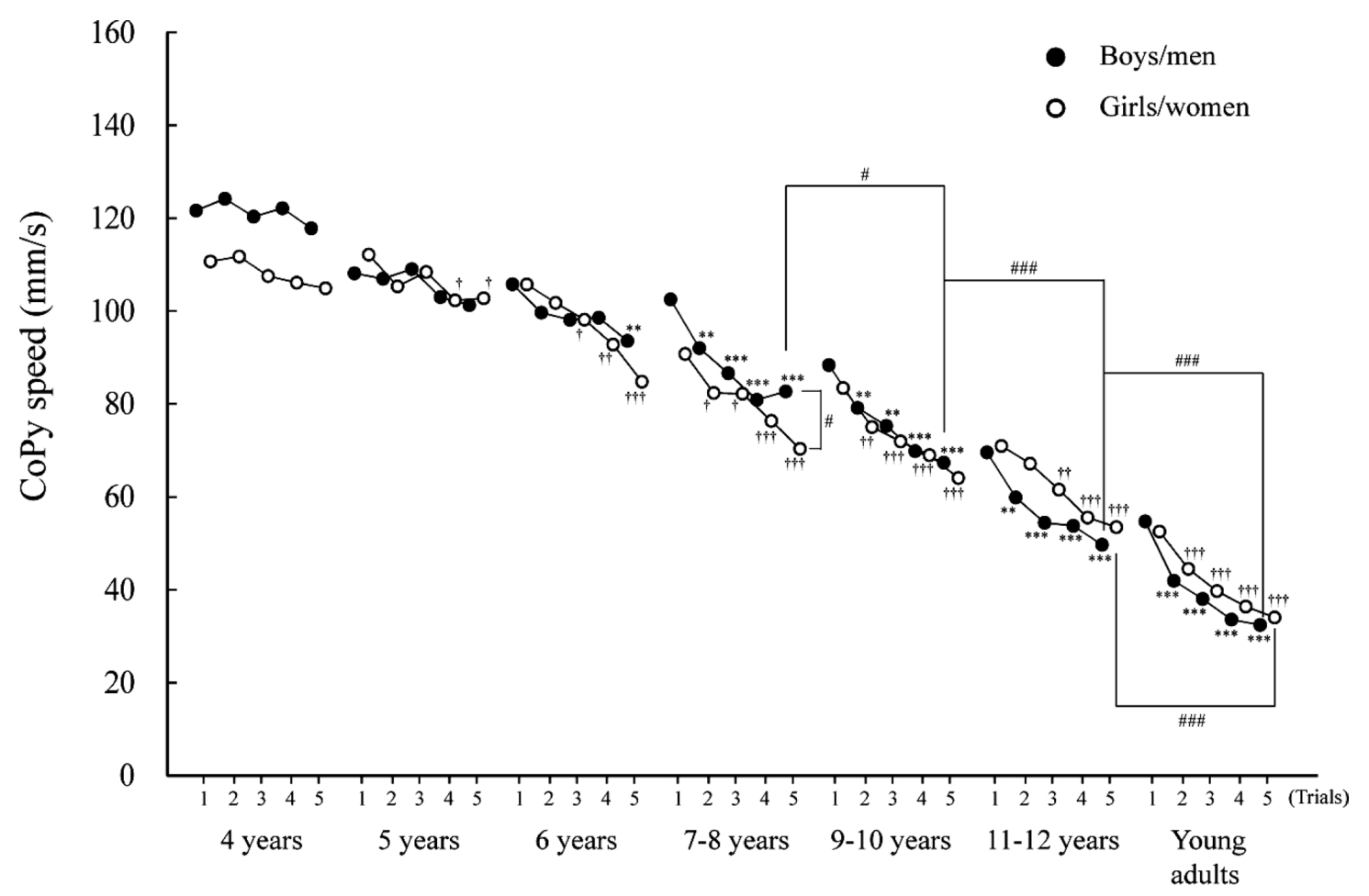

Age groups

Fig. 2 Changes in mean values of CoPy speed across five trials. Asterisks and daggers indicate significant differences relative to the first trial in boys/men and girls/women, respectively. ${ }^{* *} p<0.01, * * * p<0.001, \dagger p<0.05$, $\dagger p<0.01, \dagger \dagger p<0.001$. Sharp signs indicate significant differences in the fifth trial between adjacent age groups. ${ }^{*} p<0.05, \# \#<0.001$.

comparisons in each level of trials, age, and sex were conducted. In young adults, CoPy speed decreased rapidly until the third trial and slightly altered between the fourth and fifth trials. CoPy speed in the second and following trials for men and women was significantly lower than in the first trial $(p<0.001)$. In children, no significant decrease in CoPy speed across trials was shown in boys aged 4 and 5 or in girls aged 4. Significant decreases in CoPy speed with trial repetition were observed in boys aged 6 and older and in girls aged 5 and older $(p<0.05)$. Significant differences between the first and the third trial were shown in boys aged 7-8 and older and in girls aged 6 and older $(p<0.05)$. In children, CoPy speed in the fifth trial for boys and girls decreased as age increased (boys: $F_{6,112.3}=106.5$; girls: $F_{6,102.1}=64.4, p<0.001$ ). CoPy speed in the fifth trial for each group of children, regardless of sex, was significantly larger than in young adults $(p<0.001)$. Significant sex differences in CoPy speed in the fifth trial were observed at $7-8$ years old, and the speed in girls was significantly slower than in boys ( $7-8$ years old: $t_{72}=2.22, p<0.05$ ).

The criterion for evaluating anticipatory postural control adaptability and the correlation between CoPy speed in the first and fifth trials for children are shown in Fig. 3. Based on an adaptability criterion, the number and percentage of subjects assigned to each category are shown in Table 2. The number in both sexes significantly changed with age (boys/men: $\chi_{12}^{2}=153.6$; girls/women: $\chi_{12}^{2}=105.0, p<0.001$ ).
Until age 6 in boys (standardized residuals: $>2.3$ ) and age 5 in girls $(>4.3)$, more subjects were in the "poor" group than in the "good" or "moderate" groups. The number in the "poor" group significantly decreased with age, except for girls aged 11-12 years. On the other hand, until age $7-8$ in boys $(>-1.9)$ and age 6 in girls $(>-2.9)$, significantly fewer subjects were in the "good" category; the number in the "good" category increased with age. The number of subjects in the "good" and "poor" groups was compared between adjacent age groups. In boys, the number in the "poor" group at age 9-10 significantly decreased compared with those aged 7-8 $(p<0.05)$, and the number in the "good" group at age 11-12 significantly increased compared with age 9-10 $(p<0.05)$. In girls, no significant differences were observed, but the number in the "poor" group tended to increase from age 9-10 to 11-12, in contrast to boys. However, in both sexes, the number in the "good" group at age 11-12 was significantly lower than in young adults. The percentage distribution in each category showed a significant sex difference only at age 7-8 $(z=2.36$, $p<0.05)$. The percentage in the "poor" group was significantly smaller in girls than in boys $(p<0.05)$. 
A

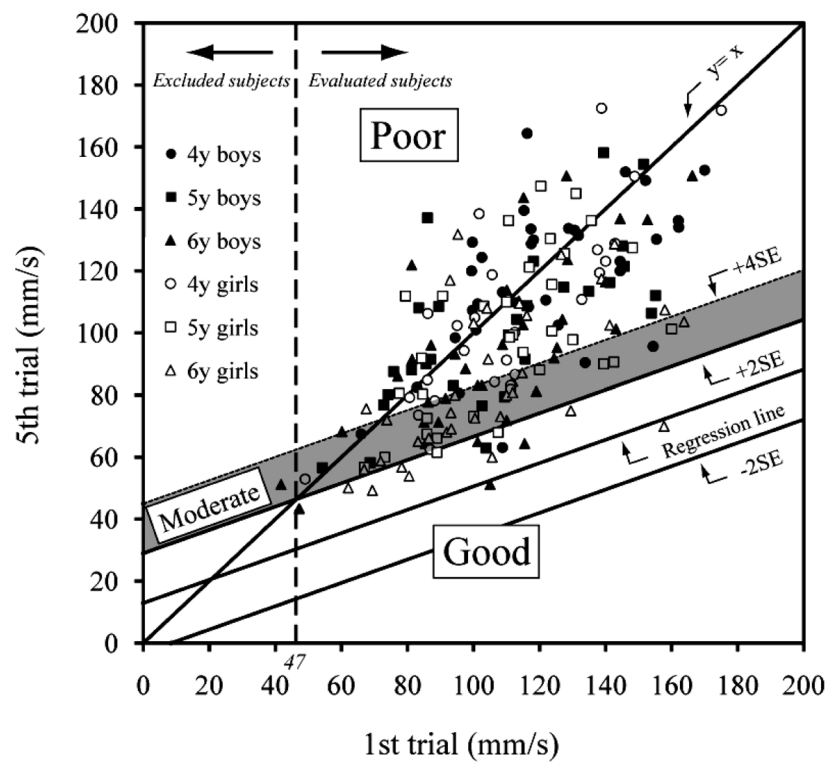

A:4-6 years
B

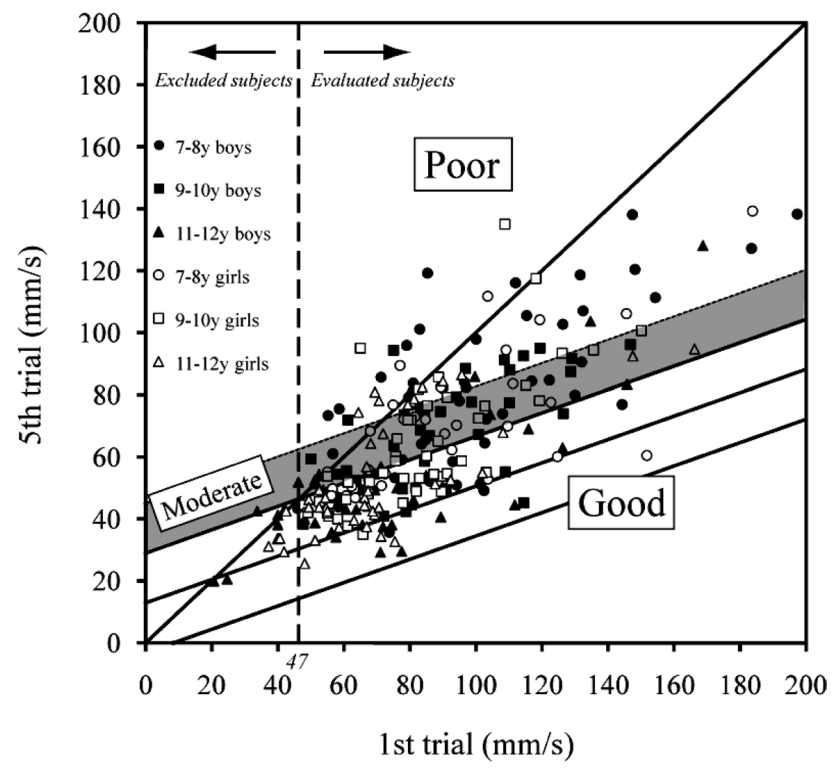

B:7-12 years

Fig. 3 Criterion of postural control adaptability and correlation between CoPy speed in the first and fifth trials in young and older children. A: young children (4-6 years); B: older children ( $7-12$ years).

Table 2 Number of subjects assigned to each category of adaptability among children and young adults

\begin{tabular}{|c|c|c|c|c|c|c|c|c|}
\hline \multirow{2}{*}{ Gender } & \multirow{2}{*}{$\begin{array}{l}\text { Age } \\
\text { group }\end{array}$} & \multirow{2}{*}{$\begin{array}{c}\text { Total } \\
\text { number }\end{array}$} & \multicolumn{2}{|c|}{ Good } & \multicolumn{2}{|c|}{ Moderate } & \multicolumn{2}{|c|}{ Poor } \\
\hline & & & $\begin{array}{c}\text { Number } \\
\left(\% \%_{\text {total }}\right)\end{array}$ & $\begin{array}{l}\text { Standardized } \\
\text { residual }\end{array}$ & $\begin{array}{c}\text { Number } \\
\left(\%_{\text {total }}\right)\end{array}$ & $\begin{array}{l}\text { Standardized } \\
\text { residual }\end{array}$ & $\begin{array}{l}\text { Number } \\
\left(\%_{\text {total }}\right)\end{array}$ & $\begin{array}{l}\text { Standardized } \\
\text { residual }\end{array}$ \\
\hline \multirow[t]{7}{*}{ Boys (men) } & 4 & 34 & $1(3 \%)$ & $-4.32^{\dagger}$ & $4(12 \%)$ & -1.40 & $29(85 \%)$ & $5.33^{*}$ \\
\hline & 5 & 29 & $1(3 \%)$ & $-3.88^{\dagger}$ & $4(14 \%)$ & -0.99 & $24(83 \%)$ & $4.57 *$ \\
\hline & 6 & 36 & $4(11 \%)$ & $-3.36^{\dagger}$ & $10(28 \%)$ & 1.11 & $22(61 \%)$ & $2.34 *$ \\
\hline & $7-8$ & 43 & $10(23 \%)$ & $-1.91^{<.10}$ & $11(26 \%)$ & 0.85 & $22(51 \%)$ & 1.16 \\
\hline & $9-10$ & 39 & $15(38 \%)$ & 0.35 & $17(44 \%)$ & $3.82 *$ & $\#\left[\begin{array}{r}7(18 \%) \\
0\end{array}\right.$ & $-3.47^{\dagger}$ \\
\hline & $11-12$ & 38 & \# L $28(74 \%)$ & $5.26^{*}$ & $6(16 \%)$ & -0.83 & $4(10 \%)$ & $-4.42^{\dagger}$ \\
\hline & Young adults & 31 & \#[ $31(100 \%)$ & $7.93 *$ & $0(0 \%)$ & -3.05 & $0(0 \%)$ & $-5.19^{\dagger}$ \\
\hline \multirow[t]{7}{*}{ Girls (women) } & 4 & 26 & $0(0 \%)$ & $-4.52^{\dagger}$ & $8(31 \%)$ & 0.50 & $18(69 \%)$ & $4.30^{*}$ \\
\hline & 5 & 34 & $2(6 \%)$ & $-4.52^{\dagger}$ & $10(29 \%)$ & 0.39 & $22(65 \%)$ & $4.40^{*}$ \\
\hline & 6 & 36 & $7(19 \%)$ & $-2.88^{\dagger}$ & $15(42 \%)$ & $2.21^{*}$ & $14(39 \%)$ & 0.95 \\
\hline & $7-8$ & 32 & $14(44 \%)$ & 0.31 & $10(31 \%)$ & 0.63 & $8(25 \%)$ & -0.92 \\
\hline & $9-10$ & 45 & $24(53 \%)$ & 1.83 & $15(33 \%)$ & 1.12 & $6(13 \%)$ & $-2.99^{\dagger}$ \\
\hline & $11-12$ & 41 & $26(63 \%)$ & $3.17^{*}$ & $6(15 \%)$ & $-1.91^{<.10}$ & $9(22 \%)$ & -1.53 \\
\hline & Young adults & 26 & ${ }^{\#} \mathrm{~L}_{26}(100 \%)$ & $6.44 *$ & $0(0 \%)$ & $-3.26^{\dagger}$ & $0(0 \%)$ & $-3.71^{\dagger}$ \\
\hline
\end{tabular}

Asterisks indicate significantly larger numbers of subjects relative to the expected frequency. Daggers indicate a significantly smaller number of subjects relative to the expected frequency. Sharp signs indicate significant differences between adjacent age groups. $* p<0.05, \dagger p<0.05$, $\# p<0.05$.

\section{Discussion}

Evaluation of the developmental process for postural control adaptability

Periodic floor oscillation in subjects standing with eyes closed is regarded as a relatively novel experimental condition. We have developed how to evaluate the adaptability of postural control, based on the degree of improvement for steadiness in standing posture, in such conditions (Fujiwara et al., 2007). This method enables the assessment of postural adaptability in a very short time period (5 minutes), allowing the acquisition of a large quantity of data. However, age-related changes and sex differences for adaptability during floor oscillation with eyes closed in childhood have not been investigated 
systematically for a large number of subjects. Thus, the present results have high utility in epidemiological studies for the developmental process in postural control adaptability.

In previous studies, we have revealed that the changes in the CoPy speed across the five trials are a useful index to evaluate the presence or absence of adaptability and adaptability speed. Moreover, the criterion based on the regression line between CoPy speeds in the first and fifth trials helps to evaluate an individual's adaptability and whether the adaptability has reached the young adult level or not (Fujiwara et al., 2007). Therefore, in the present study we used these indices and demonstrated the developmental process from premature adaptability of anticipatory postural control to adult-like adaptability based on nonvisual systems.

\section{Age-related changes and sex differences in postural control adaptability}

Forssberg and Hirschfeld (1994) distinguished two functional levels involved in the development of postural control to externally triggered disturbances. The first level is the selection of basic postural synergies, and the second level is the regulation of basic synergies based on multisensory information. It is believed that the second level of postural control regulations emerges at around 14 months of age (Sveistrup and Woollacott, 1996) and improves through postural experience up to the age of 10 (Hadders-Algra et al., 1996; Sveistrup and Woollacott, 1996; Roncesvalles et al., 2000, 2001, 2004). For this research, we chose children aged 4 to 12 years who were at the second level of functional development.

Woollacott et al. (1987) reported that at the age of 4-6 years, primary sensory information for postural control shifts from visual to somatosensory information. We demonstrated that significant adaptation changes of postural control with eyes closed were not found in children aged 4 years, but were observed from age 5 in girls and 6 in boys. These results suggest that the development of postural control adaptation in nonvisual conditions starts 1 year earlier for girls than for boys. We have also observed that a remarkable adaptability improvement appears at age 7-8 in boys and 6 in girls. Hadders-Algra (2008) reported that by these ages, postural control develops according to the multiple sensory-motor functions. Other researchers have also demonstrated that in children at these ages, vestibular function reaches the adult level (Shumway-Cook and Woollacott, 1985), the postural reference frame shifts from a body-based egocentric to a gravity-based allocentric frame (Roncesvalles et al., 2005), and the anticipatory postural control ability improves significantly (Hay and Redon, 2001). In addition, some studies have suggested that the integration of multisensory information in children aged 7-10 years enables adaptive adjustment with respect to the external environment (Forssberg and Nashner, 1982; Shumway-Cook and Woollacott, 1985; Foudriat et al., 1993). Our results showed that anticipatory postural control adaptability based on the nonvisual system develops prominently from age 5 to 10 years. This age of remarkable improvement more or less coincides with the age of a smaller growth period, before the rapid increase in adolescence. Motor skills (Kugler et al., 1980) and postural control (ShumwayCook and Woollacott, 1985) appropriately develop before and after the critical dimensional changes of the body that occur in adolescence. Therefore, it is conceivable that anticipatory postural control adaptability based on the nonvisual system develops during a smaller growth period. However, the remarkable improvement of postural adaptability could be also related to physical and sport experiences. Gabbard (2004) noted that sports and physical education are the most influential developmental factors in motor skill development and refinement during childhood and adolescence. We will address this topic of postural control adaptability in future studies.

At age 11-12, the percentage of subjects in the "good" category ( $74 \%$ in boys and $63 \%$ in girls) was still inferior to young adults $(100 \%)$. As mentioned above, the adaptability in boys was 1 year later compared with girls. However, at age 9-12, boys showed a sudden increase in adaptability and by the age of 11-12, they had caught up with girls. At age 11-12, girls showed a slight increase in the "poor" category, whereas boys showed a slight decrease. These results indicate a different neuro-motor developmental process between the sexes. Many researchers have used repetitive simple motor movements related to muscle function and shown that boys showed a more rapid development of these movements than girls (Largo et al., 2001a, b, 2003; Gasser et al., 2007). In contrast, for complex sequential movements and adaptive tasks on the pegboard, girls developed more rapidly than boys. For coordinated movements, Larson et al. (2007) demonstrated that the developmental period in girls was earlier than in boys. Riach and Hayes (1987) have noted the same earlier development in static balance in girls. A similar developmental process was also reported by anatomical magnetic resonance imaging studies, showing that the gray matter areas of the frontal and parietal cortices reach their maximum size about 1 year earlier in girls than in boys (Giedd et al., 1999). Given these findings, we suggest that sex differences in adaptability of anticipatory postural control presumably result from the development of the central nervous system, rather than the muscular system. Moreover, we suggest the involvement of the secondary sexual characteristics during puberty in the development of anticipatory postural control. It is known that the secondary sexual characteristics generally begin at 10 to 13 years in girls and 12 to 15 years in boys, and body size continues to increase for 2 or 3 more years (Gabbard, 2004; Berger, 2009). During this period, a decrease in the developmental velocity of motor controllability or a temporary slump has been also reported (Kugler et al., 1980). This study shows that anticipatory postural control adaptability in girls is temporarily disturbed due to the early puberty period. Future research will investigate the development of postural control adaptability in adolescence for both sexes. 
In summary, the present study showed the following: (1) anticipatory postural control adaptability starts to develop from age 6 in boys and 5 in girls, and greatly improves at age 7-8 in boys and 6 in girls; (2) at age 11-12, the adaptability of children has not yet reached the same level as for young adults; (3) the adaptability at age 11-12 for girls is temporarily disturbed due to their earlier puberty period.

\section{References}

Bair WN, Kiemel T, Jeka JJ, Clark JE (2007) Development of multisensory reweighting for posture control in children. Exp Brain Res 183: 435-446

Berger KS (2009) The developing person. Worth publishers, New York, 407-437

Buchanan JJ, Horak FB (1999) Emergence of postural patterns as a function of vision and translation frequency. $\mathrm{J}$ Neurophysiol 81: 2325-2339

Denckla MB (1973) Development of speed in repetitive and successive finger-movements in normal children. Dev Med Child Neurol 15: 635-645

Earhart GM, Sibley KM, Horak FB (2004) Effects of bilateral vestibular loss on podokinetic after-rotation. Exp Brain Res 155: 251-256

Forssberg H, Hirschfeld H (1994) Postural adjustments in sitting humans following external perturbations: muscle activity and kinematics. Exp Brain Res 97: 515-527

Forssberg H, Nashner LM (1982) Ontogenetic development of postural control in man: adaptation to altered support and visual conditions during stance. J Neurosci 2: 545-552

Foster EC, Sveistrup H, Woollacott MH (1996) Transitions in visual proprioception: a cross-sectional developmental study of the effect of visual flow on postural control. J Mot Behav 28: $101-112$

Foudriat BA, Di Fabio RP, Anderson JH (1993) Sensory organization of balance responses in children 3-6 years of age: a normative study with diagnostic implications. Int $\mathrm{J}$ Pediatr Otorhinolaryngol 27: 255-271

Fujiwara K, Ikegami H (1984) The characteristics of postural response in upright stance to the floor vibration. Jpn J Phys Educ 29: 251-261 [In Japanese with English Abstract]

Fujiwara K, Toyama H, Asai H, Miyaguchi A, Kunita K (1994) Adaptability of postural control during floor vibration in the elderly. In Taguchi K, Igarashi M, Mori S eds. Posture and gait: vestibular and neural front. Elsevier, Amsterdam, 135-138

Fujiwara K, Kiyota T, Maeda K, Horak FB (2007) Postural control adaptability to floor oscillation in the elderly. $\mathrm{J}$ Physiol Anthropol 26: 485-493

Gabbard C (2004) Lifelong motor development. Benjamin Cummings, San Francisco, 332-355

Gasser T, Rousson V, Caflisch J, Largo R (2007) Quantitative reference curves for associated movements in children and adolescents. Dev Med Child Neurol 49: 608-614

Giedd JN, Blumenthal J, Jeffries NO, Castellanos FX, Liu H,
Zijdenbos A, Paus T, Evans AC, Rapoport JL (1999) Brain development during childhood and adolescence: a longitudinal MRI study. Nat Neurosci 2: 861-863

Hadders-Algra M, Brogren E, Forssberg H (1996) Ontogeny of postural adjustments during sitting in infancy: variation, selection and modulation. J Physiol 15: 273-288

Hadders-Algra M (2008) Development of postural control. In Hadders-Algra M, Brogren E eds. Postural control: a key issue in developmental disorders. MacKeith Press, London, 22-73

Hay L, Redon C (2001) Development of postural adaptation to arm raising. Exp Brain Res 139: 224-232

Kugler PN, Kelso JAS, Turvey MT (1980) On the concept of coordinative structures as dissipative structures. I. Theoretical lines of convergence. In Stelmach GE, Requin J eds. Tutorials in motor behavior. Elsevier, Amsterdam, 3-47

Largo RH, Caflisch JA, Hug F, Muggli K, Molnar AA, Molinari L, Sheehy A, Gasser ST (2001a) Neuromotor development from 5 to 18 years. Part 1: timed performance. Dev Med Child Neurol 43: 436-443

Largo RH, Caflisch JA, Hug F, Muggli K, Molnar AA, Molinari L (2001b) Neuromotor development from 5 to 18 years. Part 2: associated movements. Dev Med Child Neurol 43: 444-453

Largo RH, Fischer JE, Rousson V (2003) Neuromotor development from kindergarten age to adolescence: developmental course and variability. Swiss Med Wkly 133: 193-199

Larson JC, Mostofsky SH, Goldberg MC, Cutting LE, Denckla MB, Mahone EM (2007) Effects of gender and age on motor exam in typically developing children. Dev Neuropsychol 32: $543-562$

Lee DN, Aronson E (1974) Visuoproprioceptive control of standing in human infants. Percep Psychophys 15: 529-532

Nardone A, Grasso M, Tarantola J, Corna S, Schieppati M (2000) Postural coordination in elderly subjects standing on a periodically moving platform. Arch Phys Med Rehabil 81: $1217-1223$

Riach CL, Hayes KC (1987) Maturation of postural sway in young children. Dev Med Child Neurol 29: 650-658

Roncesvalles MN, Schmitz C, Zedka M, Assaiante C, Woollacott M (2005) From egocentric to exocentric spatial orientation: development of posture control in bimanual and trunk inclination tasks. J Mot Behav 37: 404-416

Roncesvalles MN, Woollacott MH, Brown N, Jensen JL (2004) An emerging postural response: is control of the hip possible in the newly walking child? J Mot Behav 36: 147-159

Roncesvalles MN, Woollacott MH, Jensen JL (2000) The development of compensatory stepping skills in children. J Mot Behav 32: 100-111

Roncesvalles MN, Woollacott MH, Jensen JL (2001) Development of lower extremity kinetics for balance control in infants and young children. J Mot Behav 33: 180-192

Shumway-Cook A, Woollacott MH (1985) The growth of stability: postural control from a development perspective. J 
Mot Behav 17: 131-147

Sveistrup H, Woollacott MH (1996) Longitudinal development of the automatic postural response in infants. J Mot Behav 28: $58-70$

Woollacott M, Debu B, Mowatt M (1987) Neuromuscular control of posture in the infant and child: is vision dominant? J Mot Behav 19: 167-186
Received: April 7, 2011

Accepted: June 22, 2011

Correspondence to: Katsuo Fujiwara, Department of Human Movement and Health, Graduate School of Medical Science, Kanazawa University, 13-1 Takara-machi, Kanazawa, Ishikawa 920-8640, Japan

Phone: +81-76-265-2225

Fax: +81-76-234-4219

e-mail: fujikatu@med.m.kanazawa-u.ac.jp 